DOI: $10.1515 / \mathrm{adms}-2016-0019$

\title{
A. Kausar
}

Nanoscience and Technology Department, National Centre For Physics, Quaid-i-Azam

University Campus, Islamabad, Pakistan

asheesgreat@yahoo.com

\section{POLYCARBONATE/POLYPROPYLENE-GRAFT-MALEIC ANHYDRIDE AND NANO-ZEOLITE-BASED NANOCOMPOSITE MEMBRANE: MECHANICAL AND GAS SEPARATION PERFORMANCE}

\begin{abstract}
In this effort, blend membrane of polycarbonate (PC) and polypropylene-graft-maleic anhydride (PPMA) was fabricated via phase inversion technique. The nano-zeolite (NZ) was employed as nanofiller. Morphology of PC/PPMA/NZ membrane revealed unique inter-connected branched microstructure. Tensile strength and Young's Modulus of PC/PPMA/NZ 0.1-5 were in the range of 59.9-74.5 MPa and 111.4-155.2 MPa respectively. The nano-zeolite filler was also effective in enhancing the permselectivity $\alpha \mathrm{CO}_{2} / \mathrm{N}_{2}$ (23.5 to 38.5) relative to blend membrane (20.3). The permeability $\mathrm{P}_{\mathrm{CO} 2}$ of PC/PPMA/NZ 5 membrane was found as 106.2 Barrer. Filler loading enhanced gas diffusivity, however filler content did not significantly influence $\mathrm{CO}_{2}$ and $\mathrm{N}_{2}$ solubility.
\end{abstract}

Keywords: Polycarbonate, nano-zeolite, permselectivity

\section{INTRODUCTION}

Generally, polymer blends are physical mixture of structurally different polymers. The polymeric blends have distinct potential benefits owing to physical and structural properties. In thermodynamic stance, most of the polymers are immiscible. However, miscible polymer blends may engender high performance materials with unique properties and processability. Polymer blends have been prepared using variety of engineering resins and techniques, focusing wide range of applications [1,2]. As polymer blends are multi-phase systems, they may form different morphological structures such as fibres, spheres, ribbons, plates, cylindrical and other structures. The blend morphology can be varied via inclusion of nanoparticle such as silica, zeolite, carbon nanotube, and other nanofiller. One of the most widely used thermoplastic polyolefin is polypropylene (PP). It has been considered for compositing intended for the production of new nanocomposite. The maleic anhydride grafted polypropylene has been employed as compatibilizer for the production of nanocomposite [3, 4]. In this case the morphology and characteristics of final material may be varied by density of maleic anhydride groups [5]. Another important class of thermoplastic polymers is polycarbonate (PC) [6]. Polycarbonate has been considered between the commodity plastics and engineering plastics. Its chemical structure consists of carbonate group. Polycarbonate is 
strong and tough; however it is easily workable, moldable, and thermo-formed. PC has fine mechanical properties such as impact and shock resistance [7]. The glass transition temperature of polycarbonate is found $\sim 150{ }^{\circ} \mathrm{C}$. Moreover, polycarbonate has fine optical properties and thermal resistance [8]. Zeolite is considered as significant polymer filler/nanofiller. It may form micro-porous crystals with complex channels and pores. Furthermore, it is frequently exploited as an ion-exchanger, adsorbents, and catalysts [9, 10]. The size of zeolite particles may be influenced by crystallization at controlled temperature [11]. Zeolite has potential application in separation membranes due to fine adsorption and diffusion selectivity. Polycarbonate membranes reinforced with zeolite are exceptionally permeable and selective. High performance zeolite-based membranes have been achieved with easy processability, sorption characteristics, and shape selectivity of nanoparticles. Increasing zeolite content may act as adsorbing component in the membrane [12-14]. Moreover, high potential polycarbonate/zeolite mixed matrix membrane has also been developed [15]. The membrane structure and performance have been influenced by the particle size and zeolite content. Solvent evaporation methodology is commonly used for these membranes. Melt compounding has also been employed as preferred technique [16-18]. According to morphology investigation, zeolite may form large clusters in polycarbonate membrane. Moreover, permeability of PC membranes has been found to decrease with zeolite loading. Nevertheless, improvement in selectivity was observed for PC/zeolite membrane relative to neat polycarbonate membrane $[19,20]$. The zeolite strengthened polyimide and polysulfone membranes have been developed and investigated [21, 22]. Effect of surface modification of zeolite on the physical properties of polyimide hybrid films was also investigated [23, 24]. Mechanical stability of the membranes was found to increase with zeolite loading. In this attempt, nano-zeolite-based nanocomposite membranes have been developed for $\mathrm{CO}_{2} / \mathrm{N}_{2}$ separation. A blend of polycarbonate (PC) and polypropylene-graftmaleic anhydride (PPMA) was designed in this regard. The nano-zeolite reinforced PC/PPMA blend membranes possess fine $\mathrm{CO}_{2} / \mathrm{N}_{2}$ gas-separation performance and mechanical properties relative to neat blend membrane.

\section{EXPERIMENTAL}

\section{Materials}

Polypropylene-graft-maleic anhydride $\left(\mathrm{M}_{\mathrm{w}} \sim 9,100, \mathrm{M}_{\mathrm{n}} \sim 3,900\right.$, maleic anhydride 8-10 wt.\%), polycarbonate ( $\left.\mathrm{PC}, \mathrm{M}_{\mathrm{w}} \sim 50,000\right)$, zeolite $(<10 \mu \mathrm{m})$, and dimethylformamide (DMF, 99\%) were obtained from Aldrich.

\section{Measurement}

The average size of particles was also determined by dynamic light scattering method (DLS) (LPA 3000 Photal, Otsuka Electronics). Fourier transformed infrared (FTIR) spectra were recorded in the range of $400-4000 \mathrm{~cm}^{-1}$ using a Perkin-Elmer FTIR spectrometer. Field Emission Scanning Electron Microscopy (FE-SEM) was performed using JSM5910, JEOL Japan to examine freeze-fractured samples. Tensile tests of all the samples were performed using Shenzen Sans Universal Testing Machine (UTM), at ambient conditions with cross head speed of $2 \mathrm{~mm} / \mathrm{min}$ and $0.5 \mathrm{kN}$ load. Gas permeation tests were performed at $27^{\circ} \mathrm{C}$ and upstream pressure of $10 \mathrm{psi}$ [25]. The value of gas permeability $(\mathrm{P})$ was measured from Eq (1): 


$$
P=\frac{V L}{A R T \Delta P} \frac{d P}{d T}
$$

Where:

$\mathrm{V}=$ downstream volume

$\mathrm{L}=$ membrane thickness

$\mathrm{A}=$ membrane area

$\mathrm{R}=u$ niversal gas constant

$\mathrm{T}=$ absolute temperature

$\Delta \mathrm{P}=\mathrm{p}_{2}-\mathrm{p}_{1}=$ Trans membrane pressure difference; $\mathrm{p}_{2}$ and $\mathrm{p}_{1}$ upstream and downstream pressures

$\mathrm{dp} / \mathrm{dt}=$ steady rate at which pressure increases on the downstream side.

The permselectivity $(\alpha)$ was calculated using Eq (2):

Where:

$$
\alpha=\frac{P_{A}}{P_{B}}
$$

$\mathrm{P}_{\mathrm{A}}$ and $\mathrm{P}_{\mathrm{B}}$ are permeabilities of two gases

The diffusivity $(D)$ was estimated from $\mathrm{Eq}(3)$ :

Where:

$$
D=\frac{L^{2}}{\theta}
$$

$\theta=$ time lag when a steady $\mathrm{d} p / \mathrm{d} t$ rate is obtained on the downstream side

$\mathrm{L}=$ membrane thickness

The solubility $(S)$ was determined from $\mathrm{Eq}(4)$ :

$\mathrm{D}=$ diffusivity

$$
S=\frac{P}{D}
$$

$\mathrm{P}=$ permeability

Nano-zeolite formation (NZ)

Nano-zeolite was prepared using ball milling process. Zeolite powder, as obtained from Aldrich, was used for ball milling. For this purpose, ball to powder ratio was kept as 10:1. Crushed nano-zeolite powder was obtained after $96 \mathrm{~h}$ of ball milling. The powder further employed as nano-filler [26]. The average nanoparticle size determined by DLS was $75 \pm 0.1$ nm.

Polycarbonate/polypropylene-graft-maleic anhydride (PC/PPMA) membrane formation via phase inversion

The $0.3 \mathrm{~g}$ PC was dissolved in $1 \mathrm{~mL}$ DMF via $3 \mathrm{~h}$ sonication. A dispersion of $0.2 \mathrm{~g}$ PPMA was also prepared in $0.5 \mathrm{~mL}$ DMF with sonication of $2 \mathrm{~h}$. The PPMA solution was then added to the PC solution. The mixture was refluxed for $2 \mathrm{~h}$ at $80{ }^{\circ} \mathrm{C}$. The solution was cast on glass plate using knife. The glass plate was then immersed in aqueous solution for $0.5 \mathrm{~h}$. The resulting membranes were dried at $80{ }^{\circ} \mathrm{C}$ for $2 \mathrm{~h}$ [27]. 
Polycarbonate/polypropylene-graft-maleic anhydride/nano-zeolite membrane(PC/PPMA/NZ)

The phase inversion route was also used for the formation of composite membranes. $0.3 \mathrm{~g}$ PC and 0.2g PSAA was dissolved in DMF. To the mixture, desired content (1-10 wt.\%) of nano-zeolite were added (Fig. 1). The membrane composition is given in Table 1.

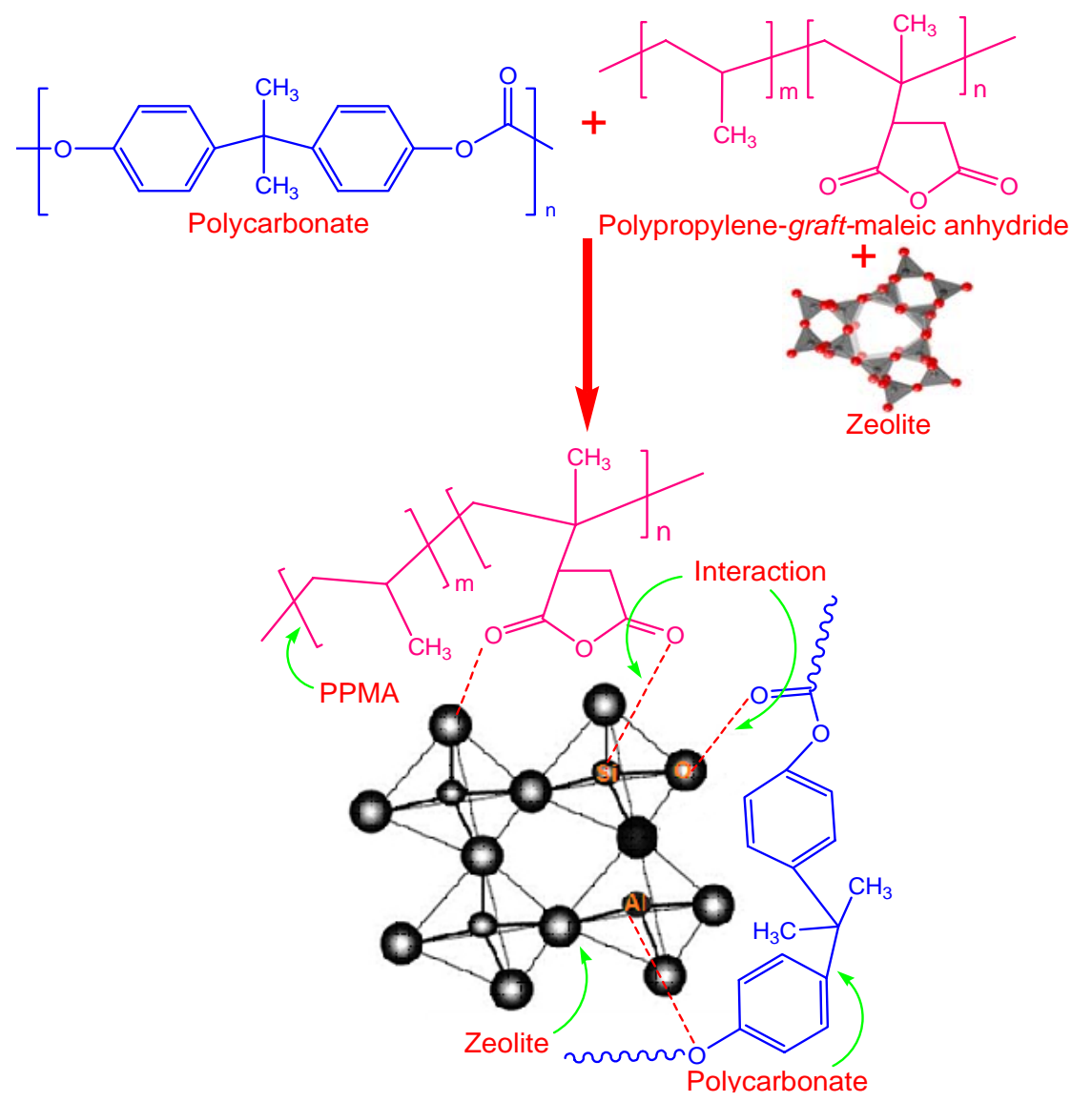

Fig. 1. Formation of polycarbonate/polypropylene-graft-maleic anhydride/nano-zeolite membrane

Table 1. Sample codes and composition used

\begin{tabular}{llccc}
\hline \multicolumn{1}{c}{ Sample } & \multicolumn{1}{c}{ Composition } & PC & PSAA & NZ (wt.\%) \\
\hline PC/PPMA & $\begin{array}{l}\text { Polycarbonate/polypropylene-graft-maleic } \\
\text { anhydride }\end{array}$ & 0.3 & 0.2 & 0 \\
PC/PPMA/NZ 0.1 & $\begin{array}{l}\text { Polycarbonate/polypropylene-graft-maleic } \\
\text { anhydride/nano-zeolite 0.1 }\end{array}$ & 0.3 & 0.2 & 0.1 \\
PC/PPMA/NZ 0.5 & $\begin{array}{l}\text { Polycarbonate/polypropylene-graft-maleic } \\
\text { anhydride/nano-zeolite 0.5 }\end{array}$ & 0.3 & 0.2 & 0.5 \\
PC/PPMA/NZ 1 & $\begin{array}{l}\text { Polycarbonate/polypropylene-graft-maleic } \\
\text { anhydride/nano-zeolite 1 }\end{array}$ & 0.3 & 0.2 & 1 \\
PC/PPMA/NZ 3 & $\begin{array}{l}\text { Polycarbonate/polypropylene-graft-maleic } \\
\text { anhydride/nano-zeolite 3 } \\
\text { Polycarbonate/polypropylene-graft-maleic } \\
\text { anhydride/nano-zeolite 5 }\end{array}$ & 0.3 & 0.2 & 3 \\
PC/PPMA/NZ 5 & 0.3 & 0.2 & 5 \\
\hline
\end{tabular}




\section{RESULTS AND DISCUSSION}

\section{Structural analysis}

FTIR spectra of PC/PPMA and PC/PPMA/NZ 1 are given in Fig. 2. In the blend spectrum, characteristic peaks of aliphatic and aromatic $\mathrm{C}-\mathrm{H}$ stretching vibration appeared at 2950 and $3011 \mathrm{~cm}^{-1}$ (Fig. 2A). The $\mathrm{C}-\mathrm{O}$ stretching vibration was found at $1230 \mathrm{~cm}^{-1}$, while the carbonate $\mathrm{C}=\mathrm{O}$ was located at $1689 \mathrm{~cm}^{-1}$. However, the symmetric and asymmetric anhydride ring carbonyl vibrations appeared at higher frequency of 1820 and $1760 \mathrm{~cm}^{-1}$ respectively. The symmetric and asymmetric anhydride carbonyl vibrations were also observed (1801 and $\left.1750 \mathrm{~cm}^{-1}\right)$ in the case of PC/PPMA/NZ 1 nanocomposite membrane (Fig. 2B). Moreover, the $\mathrm{C}=\mathrm{O}$ stretch due to polycarbonate backbone was located at $1677 \mathrm{~cm}^{-1}$. The peak at $1223 \mathrm{~cm}^{-1}$ indicated $\mathrm{C}-\mathrm{O}$ stretching vibration. The shift of characteristic absorbance peaks of $\mathrm{C}=\mathrm{O}$ carbonyl and $\mathrm{C}-\mathrm{O}$ to lower wavenumber in $\mathrm{PC} / \mathrm{PPMA} / \mathrm{NZ}$ membrane qualitatively indicated some interaction between nano-zeolite structure and the blend matrix. In addition, the peak at $3411 \mathrm{~cm}^{-1}$ corresponds to inner-hydroxyl group of nano-zeolite structure. The aliphatic and aromatic $\mathrm{C}-\mathrm{H}$ stretching vibration also appeared at 2901 and $3000 \mathrm{~cm}^{-1}$. The peak at $1250 \mathrm{~cm}^{-1}$ was the characteristic of $\mathrm{Si}-\mathrm{CH}_{2}$ functional group. The asymmetric and symmetric $\mathrm{Si}-\mathrm{O}$ stretching vibrations appeared at 1009 and $670 \mathrm{~cm}^{-1}$ [28]. Moreover, the peak for $\mathrm{Si}-\mathrm{Al}-\mathrm{O}$ appeared at $1030 \mathrm{~cm}^{-1}$.

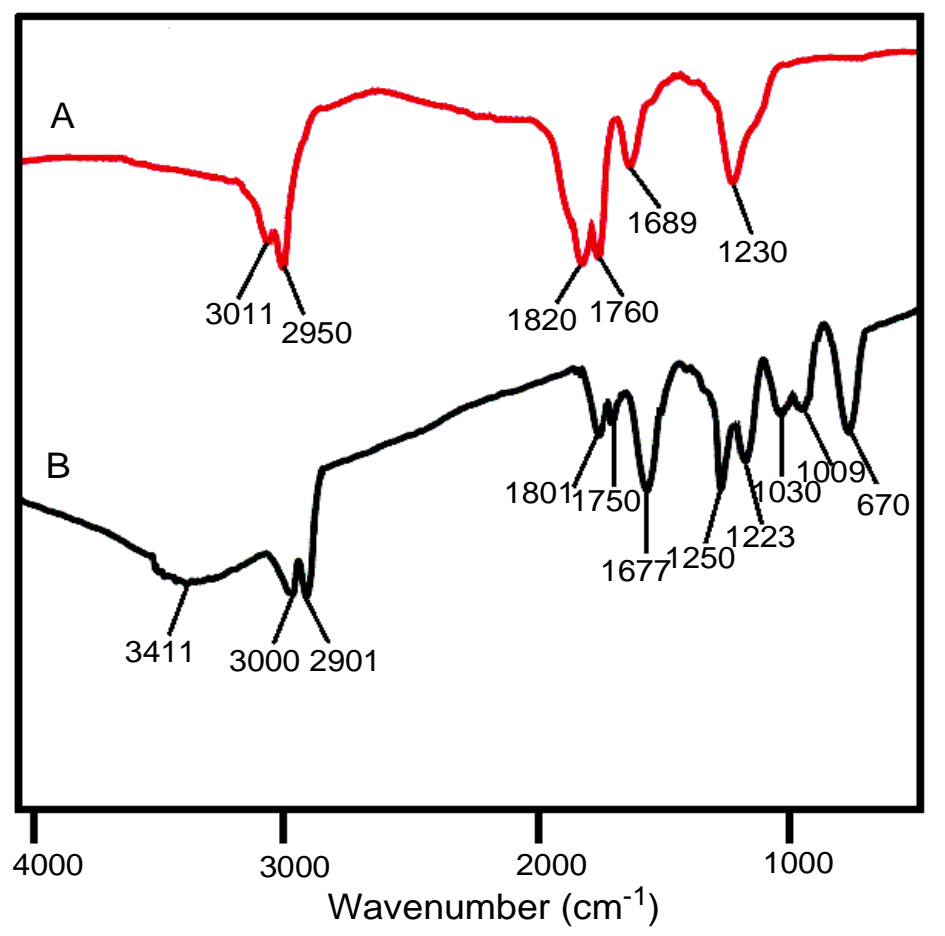

Fig. 2. FTIR spectra of (A) PC/PPMA and (B) PC/PPMA/NZ 1 membrane

\section{Mechanical property study}

Table 2 reveals the tensile stress at break, Young's modulus, and elongation at break of PC/PPMA blend and PC/PPMA/NZ nanocomposite with various nanofiller content. In the nanocomposite membrane series, tensile strength and Young's modulus were increased with nanofiller loading, however the elongation at break was found to decrease $[29,30]$. 
Table 2. Tensile strength, strain, and Young's modulus of PC/PPMA-based membranes

\begin{tabular}{lccc}
\hline \multicolumn{1}{c}{ Sample } & $\begin{array}{c}\text { Tensile stress at break } \\
(\mathrm{MPa})\end{array}$ & $\begin{array}{c}\text { Elongation at break } \\
(\%)\end{array}$ & $\begin{array}{c}\text { Young's Modulus } \\
(\mathrm{MPa})\end{array}$ \\
\hline PC/PPMA & $58.4(1.1)^{*}$ & $34.2(1.3)$ & $81.11(1.1)$ \\
PC/PPMA/NZ 0.1 & $59.9(1.2)$ & $31.1(1.1)$ & $111.4(1.3)$ \\
PC/PPMA/NZ 0.5 & $61.2(1.1)$ & $30.2(1.2)$ & $118.1(1.4)$ \\
PC/PPMA/NZ 1 & $66.5(1.2)$ & $29.9(1.2)$ & $123.3(1.2)$ \\
PC/PPMA/NZ 3 & $69.9(1.6)$ & $25.5(1.2)$ & $143.1(1.4)$ \\
PC/PPMA/NZ 5 & $74.5(1.2)$ & $23.4(1.1)$ & $155.2(1.2)$ \\
\hline
\end{tabular}

Tensile strength for neat PC/PPMA blend membrane was found to be $58.4 \mathrm{MPa}$. The strength of PC/PPMA/NZ 0.1 membrane was observed as $59.9 \mathrm{MPa}$. The property was found to increase to $61.2 \mathrm{MPa}$ with $0.5 \mathrm{wt} . \%$ nanofiller loading. Inclusion of $1 \mathrm{wt} . \%$ nano-zeolite further improved the mechanical strength to $66.5 \mathrm{MPa}$. Similarly, the property was increased for PC/PPMA/NZ 3 (69.9 MPa). In this way, the tensile stress of PC/PPMA/NZ 5 was $20 \%$ higher than the $0.1 \mathrm{wt} \%$ membrane, while $22 \%$ higher than the neat blend membrane. The higher tensile strength was observed for PC/PPMA/NZ 5 with the value of $74.5 \mathrm{MPa}$. The tensile stress results showed that the nano-zeolite addition acted as strong reinforcing agent. The mechanical property trend may be attributed to fine nano-filler orientation in the blend matrix, which significantly increased the mechanical properties of the resulting nanocomposite. The Young's modulus of PC/PPMA/NZ 0.1-5 series was increased from 111.4 to $155.2 \mathrm{MPa}$. Here, the $5 \mathrm{wt} \%$ sample showed $23 \%$ increase in Young's modulus relative to PC/PPMA/NZ 1, and 48\% increase relative to neat PC/PPMA blend. The stressstrain curves of PC/PPMA blend and PC/PPMA/NZ nanocomposite membranes are given in Fig. 3.

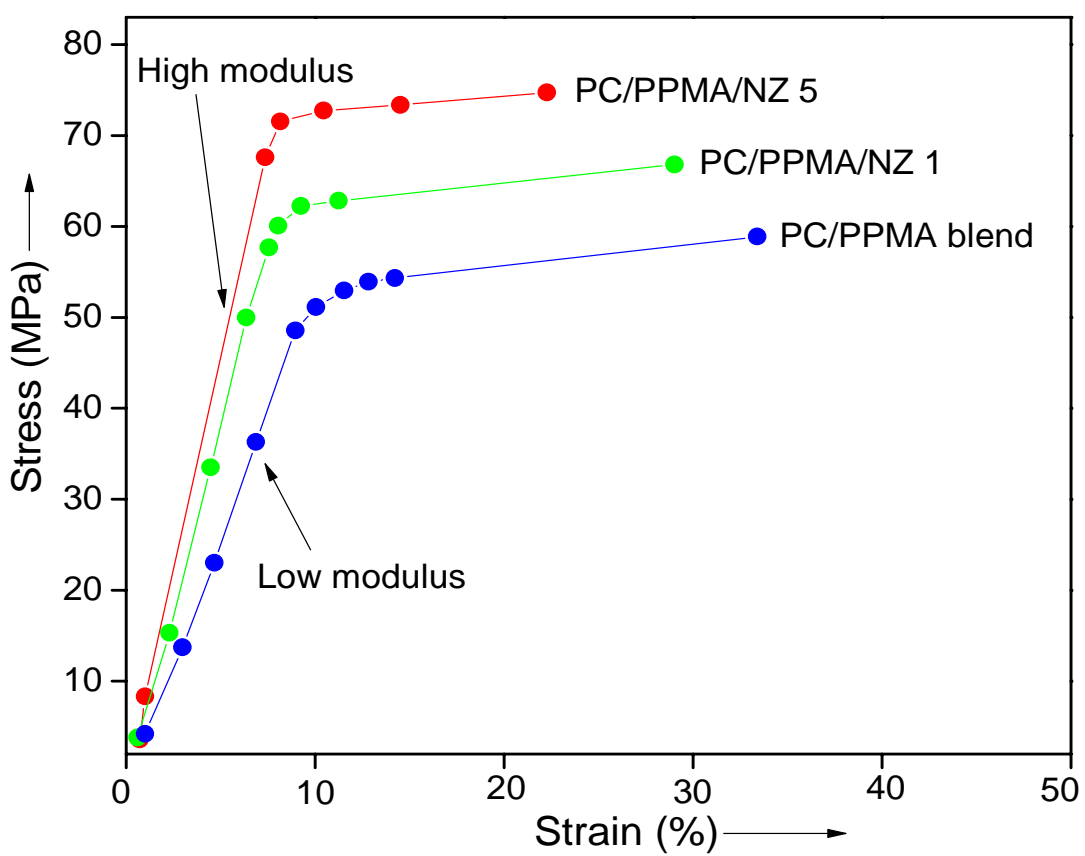

Fig. 3. Stress-strain diagram of blend, PC/PPMA/NZ 1 and PC/PPMA/NZ 5 membrane. 
The results also suggested decrease in the elongation at break of PC/PPMA/NZ 0.1-5 from 31.1 to $23.4 \%$. Neat blend had higher elongation at break value of $34.2 \%$. The zeolite nanofiller acted as interesting and promising reinforcing filler for the nanocomposite membranes. Accordingly, the membrane performance and latent in technological applications has been fundamentally improved.

\section{Morphology investigation}

The surface morphology of PC/PPMA blend and PC/PPMA/NZ membranes at micrometer length scale is given in Fig. 4.

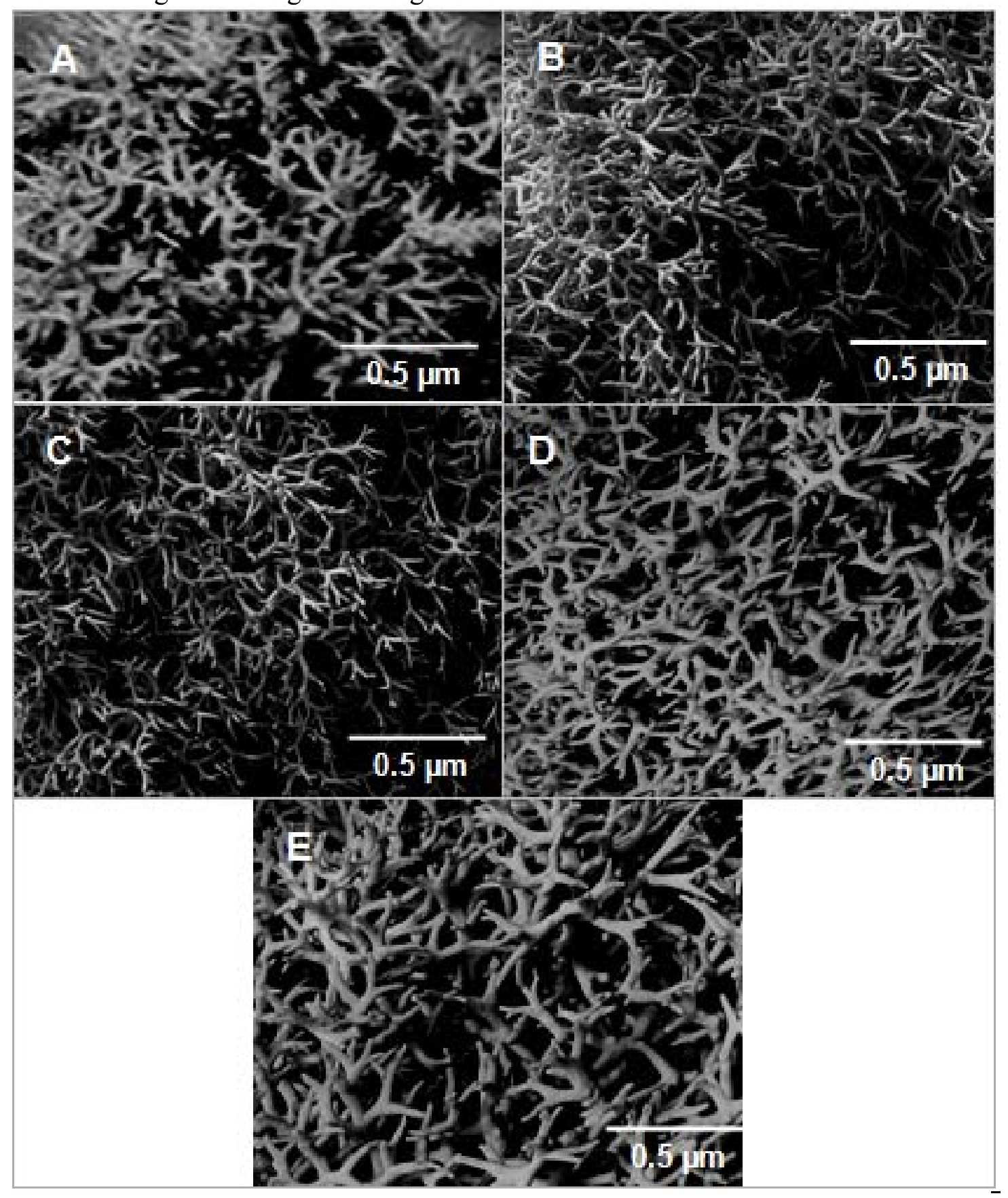

Fig. 4. FESEM images of (A) PC/PPMA blend; (B) PC/PPMA/NZ 0.5; (C) PC/PPMA/NZ 1; (D) PC/PPMA/NZ 3; and (E) PC/PPMA/NZ 5 
Assessment of the fractured surface of PC/PPMA blend revealed unique branched and entangled morphology of the two phases (Fig. 4A). It seems that the polycarbonate formed continuous phase (the matrix) in which the polypropylene-graft-maleic anhydride second phase was dispersed in some pattern. In PC/PPMA/NZ 0.5 membrane, however the nanozeolite filler content was so small; the morphology was altered with the formation of fine inter-connected branched nano-pattern (Fig. 4B). The nano-zeolite particles were not observed on the fractured surface. It seemed that the nanofiller was merged in the PC/PPMA blend. In PC/PPMA/NZ with 1 wt.\% nanofiller, the pattern showed further small branching, however the pattern was diffused at certain placed in the matrix (Fig. 4C). In PC/PPMA/NZ with 3 wt.\% nano-zeolite, the morphology attained a fine pattern due to increased filler content and better dispersion (Fig. 4D). The PC/PPMA blend formed dense pattern with somewhat elongated branches in the structure. The most finely branched and entangled pattern was observed in the case of PC/PPMA/NZ 5. Branching was again dense with the protuberated fibrils at the fracture surface (Fig. 4E). The formation of unique interconnected branched microstructure indicated fine interaction and alignment between the blend matrix and nano-zeolite. This type of morphology is unique in the case of polycarbonate and zeolite blend membranes.

\section{Gas separation performance of PC/PPMA and nano-zeolite-based membrane}

Generally, gas permeability is affected by nanofiller distribution and matrix/nanofiller alignment $[31,32]$. The permeability and permselectivity of PC/PPMA-based nanocomposite membrane as a function of filler concentration is given in Table 3. The PC/PPMA blend has permeability $P \mathrm{PO}_{2}$ of 177.2 Barrer and permselectivity $\alpha \mathrm{CO}_{2} / \mathrm{N}_{2}$ of 20.3. The membrane with 1 wt.\% filler revealed permeability $P C \mathrm{O}_{2}$ of 173.1 Barrer and permselectivity $\alpha \mathrm{CO}_{2} / \mathrm{N}_{2}$ of 23.5. The $\mathrm{CO}_{2}$ permselectivity of PC/PPMA-based nanocomposite membrane was increased with increasing the filler concentration. The $\alpha \mathrm{CO}_{2} / \mathrm{N}_{2}$ of PC/PPMA/NZ 5 membrane reached 38.5 at 5 wt. $\%$ filler content i.e. the permselectivity was $38 \%$ increased with respect to 0.1 wt.\% sample and $47 \%$ increased relative to the blend sample. However, $\mathrm{PCO}_{2}$ of PC/PPMA/NZ 0.5 membrane was 170.5 Barrer, which was further decreased to 162.2 Barrer in PC/PPMA/NZ 1 membrane.

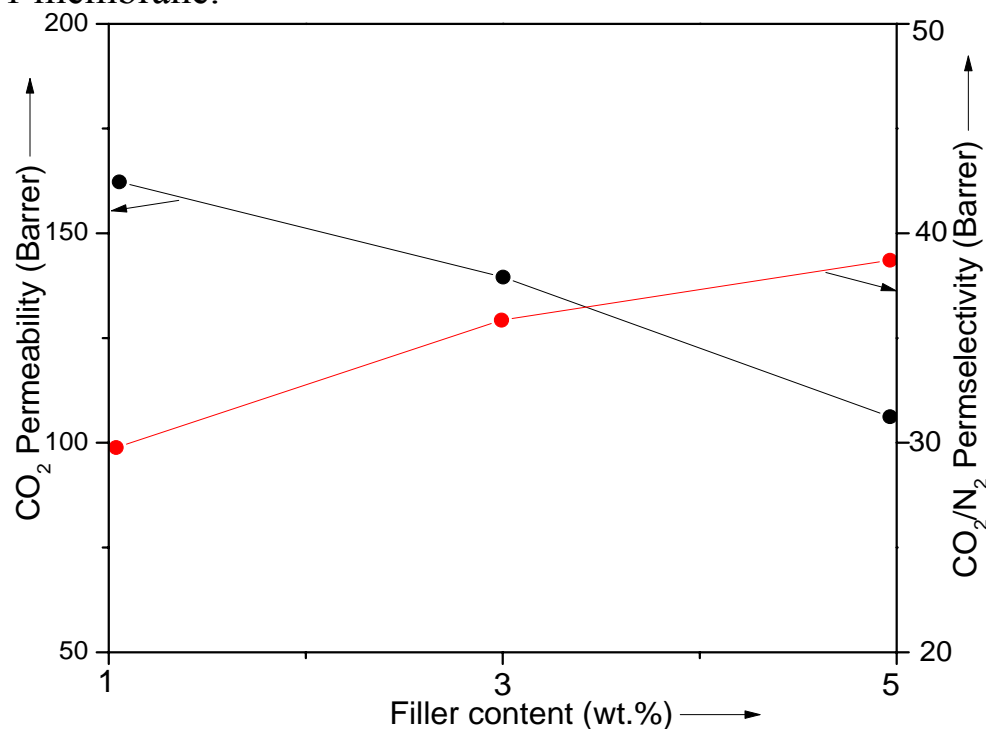

Fig. 5. Permeability and permselectivity of PC/PPMA/NZ nanocomposite membranes as a function of filler content 
The 5 wt.\% nano-zeolite loaded PC/PPMA/NZ 5 showed $\mathrm{PCO}_{2}$ of 106.2 Barrer i.e. the permeability was decreased. In this way, the permeability $P \mathrm{CO}_{2}$ of nanocomposite membrane was several fold decreased with the nanofiller addition. It seems that the $\mathrm{NZ}$ was found more effective than the nano-zeolite in enhancing the permselectivity and decreasing the $\mathrm{CO}_{2}$ permeability (Fig. 5). Further scrutiny suggested that the $\mathrm{CO}_{2}$ and $\mathrm{N}_{2}$ diffusivity was also increased with the nanofiller loading in the membranes. Fig. 6 shows that the $\mathrm{N}_{2}$ and $\mathrm{CO}_{2}$ diffusivity of the $5 \mathrm{wt} \% \%$ nanocomposite membrane was found higher than the blend membrane. Moreover, the nanofiller content did not significantly influence the $\mathrm{CO}_{2}$ and $\mathrm{N}_{2}$ solubility in the PC/PPMA/NZ membranes [33]. The overall results suggest that the adding nano-zeolite improved the gas separation properties rather than deteriorating them. Fig. 7 shows a proposed model for surge of gas molecules through of zeolite-filled membrane. The mass transport through a zeolite layer is qualitatively imagined by a four step model $[34,35]$. Four steps are expected to involve including (i) adsorption: from gas phase to membrane surface; (ii) mass transport: from surface to zeolite pores; (iii) intra-zeolite diffusion; and (iv) diffusion: out of zeolite pores to membrane surface.

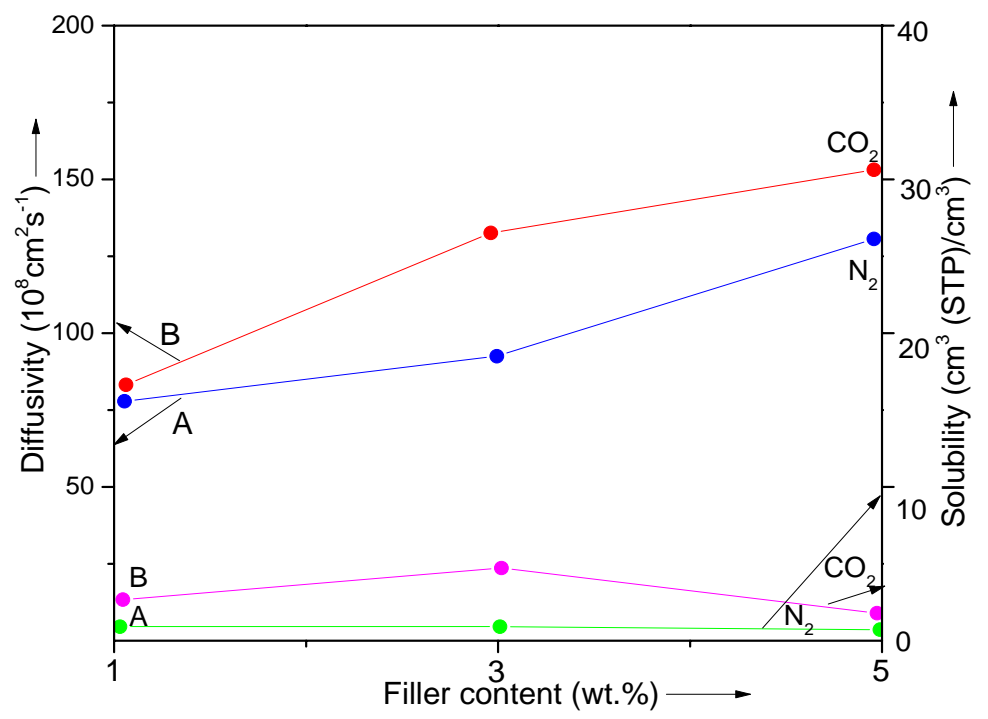

Fig. 6. CO2/N2 separation performance in terms of diffusivity and solubility for PC/PPMA/NZ nanocomposite membranes as a function of filler concentration.

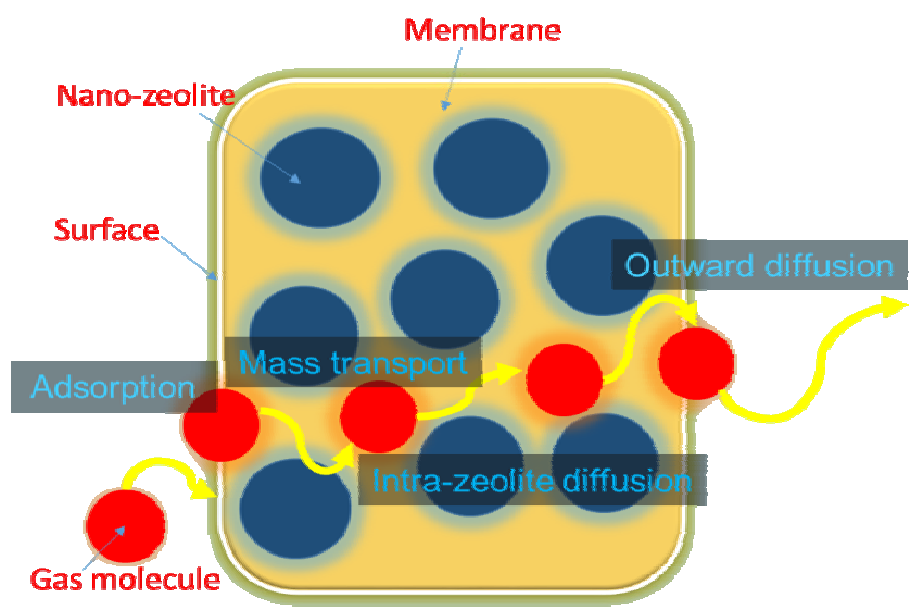

Fig. 7. Model for surge of gas molecules through zeolite membrane 


\section{CONCLUSIONS}

The nano-zeolite membranes impregnated with polycarbonate/polypropylene-graftmaleic anhydride possesses fine morphology due to better compatibility and interaction of nanofiller with the polymer blend. Nano-zeolite content was varied between 1 to $5 \mathrm{wt} . \%$, for a selected blend composition. The nano-zeolite was found to enhance the tensile strength and modulus of nanocomposite membranes, relative to the blend membranes. The tensile stress of 5 wt. $\%$ nanofiller-based PC/PPMA/NZ 5 was found to be $22 \%$ higher than the neat blend membrane. Alternatively, the elongation at break was found to decrease. The $\mathrm{CO}_{2}$ permeability of PC/PPMA/NZ 1-5 membrane was decreased from 177.2 to 106.2 Barrer. High NZ concentration (5 wt.\%) enhanced the $\mathrm{CO}_{2}$ selectivity $\alpha \mathrm{CO}_{2} / \mathrm{N}_{2}$ to 38.5. Moreover, the gas diffusivity of PC/PPMA/NZ 1-5 membrane was found higher than that of blend membrane. Conclusively, better mechanical properties of polycarbonate blend membranes can be achieved, without deteriorating the gas separation performance, through the addition of nano-zeolite filler.

\section{REFERENCES}

1. Kausar A., Ullah W., Muhammad B., Siddiq, M.: Novel mechanically stable, heat resistant and nonflammable functionalized polystyrene/expanded graphite nanocomposites, Adv. Mater. Sci. 14 (2014) 61-74.

2. Kausar A.: Effect of nanofiller dispersion on morphology, mechanical and conducting properties of electroactive shape memory Poly (urethane-urea)/functional nanodiamond composite, Adv. Mater. Sci. 15 (2015) 14-28.

3. Budzik M., Pilawka R., Imielińska K., Jumel J., Shanahan M.: Fracture of Aluminium Joints Bonded with Epoxy Adhesive Reinforced by MMT Nanoparticles. Adv. Mater. Sci. 9 (2009) 411 .

4. Seramak T., Serbiński W., Zieliński, A.: Porous biomaterial for orthopaedic implants based on titanium alloy, Adv. Mater. Sci. 11(2011) 27-34.

5. El-Sabbagh S.H., Mahmoud D.S., Zawrah M. F., Ahmed N. M., Sabaa M.W.: Investigation on the properties of rubber composites containing modified clay, Pigment. Resin. Technol. 44 (2015) 131-142.

6. Liu Y., Zhu X., Wang S., Zhao M.: Surface imprinted superparamagnetic nanoparticles for rapid and efficient extraction of bisphenol A form water samples, J. Chin. Adv. Mater. Soc. 1 (2013) $166-176$.

7. Patel R., Kim S. J., Roh D. K., Kim. J. H: Synthesis of amphiphilic PCZ-r-PEG nanostructural copolymers and their use in $\mathrm{CO}_{2} / \mathrm{N}_{2}$ separation membranes, Chem. Eng. J. 254 (2014) 46-53.

8. Bushell A.F., Attfield M.P., Mason C.R., Budd P.M., Yampolskii Y., Starannikova L., Rebrov A., Bazzarelli F., Bernardo P., Jansen J.C., Lanč, M.: Gas permeation parameters of mixed matrix membranes based on the polymer of intrinsic microporosity PIM-1 and the zeolitic imidazolate framework ZIF-8. J. membran. sci. 427 (2013) 48-62.

9. Muntha S. T., Kausar A., Siddiq. M.: A Review on Zeolite Reinforced Polymeric Membranes: Salient Features and Applications, Polym. Plast. Technol. Engineer. (2016) DOI:10.1080/03602559.2016.1185631. 
10. Rutkowska M., Chmielarz L., Macina D., Dudek B., Van Oers C., Cool P.: Hierarchical materials originated from mesoporous MCF material and Beta zeolite nanoparticles-synthesis and catalytic activity in $\mathrm{N}_{2} \mathrm{O}$ decomposition, J. Chin. Adv. Mater. Soc. 1 (2013) 48-55.

11. Yao J., Wang H.: Zeolitic imidazolate framework composite membranes and thin films: synthesis and applications, Chem. Soc. Rev. 43 (2014) 4470-4493.

12. Ghosh A. K., Hoek E. M., Impacts of support membrane structure and chemistry on polyamidepolysulfone interfacial composite membranes, J. Membr. Sci. 336 (2009) 140-148.

13. Kim M., Lee S.: Characteristics of porous polycarbonate membrane with polyethylene glycol in supercritical $\mathrm{CO}_{2}$ and effect of its porosity on tearing stress, J. Supercrit. Fluids. 31 (2004) 217225.

14. Li Y., He G., Wang S., Yu S., Pan F., Wu, H., Jiang, Z.: Recent advances in the fabrication of advanced composite membranes, J. Mater. Chem. A. 1 (2013) 10058-10077.

15. Kim S., Lee Y.M.: Rigid and microporous polymers for gas separation membranes, Prog. Polym. Sci. 43 (2015) 1-32.

16. Sanders D.F., Smith Z.P., Guo R., Robeson L.M., McGrath J.E., Paul D.R., Freeman B.D.: Energy-efficient polymeric gas separation membranes for a sustainable future: a review, Polymer. 54 (2013) 4729-4761.

17. Ali W., Kausar A., Iqbal T.: Reinforcement of high performance polystyrene/polyamide/polythiophene with multi-walled carbon nanotube obtained through various routes, Compos. Interfac. 22 (2015) 885-897.

18. Mehwish N. Kausar A., Siddiq M.: Polyvinylidenefluoride/Poly(styrene-butadiene-styrene)/Silver Nanoparticle-Grafted-Acid Chloride Functional MWCNTs-Based Nanocomposites: Preparation and Properties, Polym. Plast. Technol. Engineer. 54 (2015) 474-483.

19. Kim J., Son Y.: Effects of matrix viscosity, mixing method and annealing on the electrical conductivity of injection molded polycarbonate/MWCNT nanocomposites, Polymer. 88 (2016) 29-35.

20. Tian Z., Dai S., Jiang D.E.: Expanded porphyrins as two-dimensional porous membranes for CO2 separation, A.C.S. Appl. Mater. Interface. 7 (2015) 13073-13079.

21. Kausar A.: Proton exchange fuel cell membranes of poly(benzimidazole-amide)/sulfonated polystyrene/titania nanoparticles-grafted-multi-walled carbon nanotubes, J. Plast. Film. Sheet. (2014) 8756087914526879.

22. Yampolskii Y.: Polymeric gas separation membranes, Macromolecules. 45 (2012) 3298-3311.

23. Aroon M.A., Ismail A.F., Matsuura T., Montazer-Rahmati M.M.: Performance studies of mixed matrix membranes for gas separation: a review, Separat. Purificat. Technol. 75 (2010) 229-242.

24. Süer M.G., Baç N., Yilmaz, L.: Gas permeation characteristics of polymer-zeolite mixed matrix membranes. J. Membran. Sci. 91 (1994) 77-86.

25. Koros W.J., Chan A. H., Paul D. R.: Sorption and transport of various gases in polycarbonate, J. Membran. Sci. 21 (977) 165-190.

26. Charkhi A., Kazemian H., Kazemeini M.: Optimized experimental design for natural clinoptilolite zeolite ball milling to produce nano powders, Powder. Technol. 203 (2010) 389396.

27. Pinnau I., Koros W. J.: Structures and gas separation properties of asymmetric polysulfone membranes made by dry, wet, and dry/wet phase inversion, J. Appl. Polym. Sci. 43 (1991) 14911502. 
28. Fathizadeh M., Aroujalian A., Raisi A.: Effect of added NaX nano-zeolite into polyamide as a top thin layer of membrane on water flux and salt rejection in a reverse osmosis process, J. Membran. Sci. 375 (2011) 88-95.

29. O’Brien-Abraham J., Kanezashi M., Lin Y.S.: A comparative study on permeation and mechanical properties of random and oriented MFI-type zeolite membranes, Micropor. Mesopor. Mater. 105 (2007) 140-148.

30. Jia M. D., Pleinemann K. V., Behling R. D.: Preparation and characterization of thin-film zeolitePDMS composite membranes, J. Membran. Sci. 73 (1992) 119-128.

31. Vu D.Q., Koros W.J., Miller S.J.: Mixed matrix membranes using carbon molecular sieves: I. Preparation and experimental results, J. Membran. Sci. 211 (2003) 311-334.

32. Merkel T. C., Freeman B. D., Spontak R. J., He Z., Pinnau I., Meakin P., Hill A. J.: Sorption, transport, and structural evidence for enhanced free volume in poly (4-methyl-2-pentyne)/fumed silica nanocomposite membranes, Chem. Mater. 15 (2003) 109-123.

33. Ahn J., Chung W.J., Pinnau I., Guiver M.D.: Polysulfone/silica nanoparticle mixed-matrix membranes for gas separation. J. Membran. Sci. 314 (2008) 123-133.

34. Bakker, W.J., Kapteijn, F., Poppe, J. and Moulijn, J.A., 1996. Permeation characteristics of a metal-supported silicalite-1 zeolite membrane. J. Membran. Sci. 117 (1996) 57-78.

35. Barrer, R.M. Porous crystal membranes. J. Chem. Soc. Faraday Trans. 86 (1990) 1123-1130. 